\title{
'If I had a family, there is no way that I could afford to work here': Juggling paid and unpaid care work in social services
}

\author{
Ian Cunningham, Department of Human Resource Management, University of Strathclyde, \\ Glasgow
}

Sara Charlesworth, School of Management, RMIT University, Melbourne

Donna Baines, Social Work and Social Policy, University of Sydney

\begin{abstract}
Drawing on three case studies in each of Australia, New Zealand and Scotland, this article explores how care workers employed in the social services sector negotiate their unpaid care responsibilities in the context of lean work organisation and low pay. For younger workers, the unrelenting demands of service provision and low pay made any long term commitment to working in social services unrealistic, while many female workers experienced significant stress as they bent their unpaid care responsibilities to the demands of their paid work. However male workers, less likely to have primary caring responsibilities, appeared less troubled by the prioritising of paid over unpaid care work and less likely to self-exploit for the job. At the same time there was a widespread acceptance across different national and organizational contexts that the work/family juggle is a personal responsibility rather than a structural problem caused by the demands of underfunded and overstretched organisations.
\end{abstract}

Keywords: social services, gender, paid care work, work and family

\section{Introduction}

A substantial literature problematises the devaluation of paid care work as a consequence of its connection to the unpaid caring work women have traditionally performed in the home and community (England, 2005; Folbre, 2008; Meagher, 2006; Palmer and Eveline, 2013). However, there have been relatively few studies exploring how front line care workers 
negotiate their paid and unpaid care responsibilities, including in the expanding 'work and family' research terrain.

This article focuses on frontline care workers employed in the non-profit community or social services sector in three large multi-service non-profit social services (NPSS) organizations in Australia, New Zealand (NZ) and Scotland. In all three jurisdictions, the number of social services workers is growing, even in NZ and Scotland where employment generally has been flat or decreasing, with women accounting for around $80 \%$ of employees (Statistics NZ, 2012; ABS, 2011; SSSC, 2012). The non-profit sector is characterised by nonstandard employment. In Australia and Scotland, for example, the majority of social services workers are employed less than full-time (ABS, 2011; SSSC, 2012). Low wages and poor conditions are a feature of the sector although they are often thought to be buffered by the opportunity to work in tandem with one's personal values (Cunningham and James 2011, p. 229). Poor wages and conditions are an aspect the outsourcing of social services ongoing inadequate government funding and demands for efficiency, accountability and lean production (Baines, 2010; Cunningham, 2008; Jorgensen et al., 2009). They are underpinned by gendered expectations of self-sacrifice by workers (Charlesworth and Marshall, 2011).

This paper explores how care workers in three different organizational and national contexts managed their unpaid care responsibilities at work and how they negotiated the boundaries between paid and unpaid care. Our purpose is to investigate how care workers 'fit' work and family together and with what consequences (Moen, 2011, p. 92). To that end we explore the following questions: How does the specific NPSS context shape the negotiation of paid and unpaid care work by workers? What are the experiences of workers who manage both paid and unpaid care work in the NPSS and are these experiences different for men and women? Our paper makes a specific contribution to better understanding the social reproduction that underpins work in the NPSS and to illuminating the often hidden unpaid caring responsibilities of care workers.

In the next section we briefly outline key intersecting contexts and theoretical framings for our analysis in the literature on care work, on the social services sector and on work and family. After describing our study and the case study approach taken in the following 
section, we then take up a number of relevant themes around the negotiating of paid and unpaid care work that emerged in analysis of the case study data. These include the effects of low pay and its trade-offs, 'inflexible flexibility' and the role of supervisors, and the gendered boundaries between paid and unpaid care work, all underpinned by the low pay and lean work organisation that characterises the NPSS sector.

\section{Theoretical framings}

To understand how frontline care workers in NPSS organizations negotiate paid and unpaid work requires a multi-theoretical approach (Cunningham and James, 2011, pp. 232-233). Our analysis is broadly informed by feminist perspectives on the valuing of care work and the doing of gender in organisations. In particular we draw on Acker's insights that organisations, not just individuals are gendered (2006), in ways that both rely on and reproduce the 'unencumbered worker' through the organisation of work (Acker 1998).

\section{Gender and care work}

As Daly (2002) points out, care is one of the original feminist concepts and has developed to include not only recognition of the material and ideological processes which confirm women in the social and informal role of carer but also of paid care work and its connection with public policy and the state (p. 252-253). Paid care work has been conceptualised as 'providing face to face services that strengthen the physical health and safety or the physical, cognitive or emotional skills of those they serve' (England, Budig and Folbre, 2002, p. 455). The undervaluing of paid care work is the subject of a significant literature with an important strand providing a range of explanations for the relative low pay of care workers compared to similarly skilled workers (England et al., 2002; Folbre, 2001; Rasmussen, 2004). England (2005) identifies two relevant frameworks. The devaluation perspective argues care jobs are badly paid because they are overwhelmingly held by women and because care work is associated with the quintessentially gendered role of women, in particular mothers (England, 2005, p. 395). Indeed while both male and female care workers are economically disadvantaged in most OECD countries, the care work wage penalties for women are more severe (England, 2005, p. 458). Another perspective, the prisoner of love thesis (see Folbre, 
2001) focuses on the intrinsic motives that drive many care workers, which make it easier both for the work in care work to be hidden and for employers to justify low wages (England, 2005). Both perspectives are useful for understanding the invisibility of the unpaid caring responsibilities of paid care workers. If paid care work is inherently devalued because it is mainly carried out by women, it is not surprising that the family responsibilities of care workers are assumed as natural and hidden from view.

While formal care is increasingly marketised, its links with the unpaid care work women do for free lingers in the funding and organisation of work in the NPSS. The skills required in care work are understood as personal to the service provider and since women mainly provide these services, these skills and women's assumed natural abilities for emotional work are expected to be available to employers when they are hired (Rasmussen, 2004, p. 511). In many ways then the highly gendered nature of care work provides a sector-wide institutional logic (McDonald and Charlesworth, 2011) that shapes the expectations that employers, clients, communities and workers themselves have of the predominantly female workforce's capacity to provide elastic and endless care regardless of wages and working conditions (Charlesworth, 2010).

\section{Low pay and lean work organisation}

The delivery of social services in most industrialised countries has been profoundly affected by the shift to the market that sought to transfer economic responsibilities from the state to civil society (Bach and Bordongna, 2011; Duncan and Campbell, 2011). The outsourcing of social services in particular has been accompanied by neo-liberal governance or New Public Management (NPM). Managerialist outcome-based models and their explicit and implicit demands for efficiency and value for money, accountability and lean production have been taken up to varying degrees in different countries (Baines, 2004; Evans, Richmond and Shields, 2005; Cunningham and James, 2011). The NPM-inspired cutting and controlling of costs by increasing accountability and strongly controlling performance impacts directly on front line care workers, who are held responsible for providing the services but are unable to influence the use of resources (Rasmussen 2004, p. 510). While in the past the NPSS sector supplemented and extended the government provision of social services, today organizations in the sector 'provide social care at lower costs to a wide range of excluded 
and mainstream populations no longer serviced by the state' (Baines, Charlesworth and Cunningham, 2014a, p. 3).

The transfer of the delivery of many social services to the non-government sector to contain spending has had a direct impact on wages and conditions for workers (Kosny and MacEachen, 2010, p. 360). In the marketised NPSS, managerialist, outcomes-based models such as NPM are manifested differently across national settings and in different program areas mediated by country-specific legal and institutional and cultural traditions (Baines, Charlesworth and Cunningham, 2014b; Bach and Bordogona, 2011). What is broadly consistent across most countries is a growth in nonstandard or atypical employment in the contracted out sectors (Bach and Bordongna, 2011, p. 2287). In the NPSS, in particular, outsourcing has brought with it not only low wages but also increasing workloads, closer monitoring and bureaucracy, understaffing and stress brought on by the pressures of the external environment that many care workers feel compromises their ability to provide quality services (Cunningham and James, 2011, p.277).

Labour process scholarship has highlighted the production and consequences of lean work organisation in the NPSS sector. Analyses of the impact of funding models and the adequacy of funding suggest that the impact of outsourcing has had profound consequences for employees' working conditions more generally, including work intensification, increasing demands for documentation and workplace violence (Baines and Cunningham, 2011; Cunningham, 2008; Baines, 2004, 2010; Aronson and Smith, 2010;). Further, because the outcome measures imposed on social services organizations fail to recognise the workload and the complexity of the work needed to deliver services on the ground, there are direct consequences for workers' capacity to manage their paid and unpaid care work. Underfunded services and rising social disadvantage place stress on services and workers, making it hard for them to place their own needs above those to whom they provide care and easy for organizations to rely on gendered expectations of self-sacrifice (Charlesworth and Baines, 2011).

Another important consequence of the lean work organisation produced through tight budgets is the challenge it presents to the social justice values held by many workers (Baines, 2010; Rasmussen, 2004). Experiences in a number of countries suggest that among 
NPSS workers there are high levels of commitment based on prior orientations of altruism and commitment to the wellbeing of vulnerable groups, related political and ideological beliefs and a desire to care (Cunningham and James, 2011, p. 227; Baines, 2011a; McDonald and Charlesworth, 2011). Workers may feel positive about making changes that help and empower those to whom they provide services but may also be very frustrated by changes in the labour process that increase the pace and volume of their work, crowding out the time and energy they have for unpaid care.

\section{Work and family}

The scholarship around the interaction of work and family has burgeoned in the last two decades, focused on the growing pressures on workers, families and workplaces with the increased labour force participation of women and also on state level or workplace policies designed to 'deal' with these pressures (for a review see Bianchi and Milkie, 2010). ${ }^{1}$ Women's increased employment participation and the shift from a male breadwinner/female caregiver model of work-family relations has two key effects; it increases the resources available to meet the needs of families and communities while also intensifying the demands on women's money and time (Folbre, 2006, p. 185). This is because while dual earner families are now the norm, diverse policy reforms have contributed to a 'dual earner, gender specialized family model' (Daly 2011, p. 19).

The fact that institutions such as workplaces and the domestic division of labour have remained relatively unchanged has led to an increase in tensions, borne overwhelmingly by women, at the intersections between work and family (Pocock, 2003). While not commonly framed as a work/family concern, the social services sector provides some of the critical care infrastructure that allows many women to engage in paid employment while also creating pressure for more wide-spread services in a contracted-out state. At the same time while the sector is a growing employer of women in most industrialised countries, the low wages and poor conditions that characterise the sector provide an inadequate basis for employee work-family balance.

While there are many studies of how middle-class and professional women (and increasingly men) manage work and family, there is now growing interest in the situation of low-paid 
workers, for whom securing sufficient income may be a more pressing concern than balancing work and home life (Emilie and Hunt, 2009, p. 167). Several studies have found more gendered patterns of work and care among the low-waged where it is women, rather than men, who bend their jobs to meet family needs (Warren et al., 2009, p. 177; Weigt and Solomon, 2008). Having access to predictable, bounded working hours and to informal support through supervisors appears to be more crucial for low-waged women than women in professional positions (Weigt and Solomon, 2008). Indeed, line supervisors appear to be very important in mitigating (or not) the stress and strain involved in paid care work (Palmer and Eveline, 2013; Rubery and Urwin, 2011). Supportive extended family networks are also vital to lessen the shortfalls of low-wage work both financially and in terms of informal care provision (Weight and Solomon, 2008, p. 639).

Workers' negotiation of work and care takes place within gendered work and care regimes (Pocock, 2005) and workplaces in which a gender division of labour, gendered hierarchies of power, a gendered culture, and gender patterns of personal and emotional relations among staff are embedded (Connell, 2005, p. 374). Hobson (2011) employs Sen's capabilities framework to also highlight the complex interplay of structure and agency in the negotiation of work and family at the workplace level and the tensions that arise for workers in realising the work-family balance to which they aspire. Indeed some of these tensions arise because employer efforts to accommodate work and care are predicated on the gender division of labour, which limit the 'genuine choices' workers can make about balancing work and care (Lewis and Giullari, 2005, p. 89). For example, most workplace work-family policies, where they exist, provide in practice for the domestic responsibilities of women (Connell 2005, p. 375). While they may be expressed in gender-neutral terms, such policies are taken up overwhelmingly by women, who are seen as responsible for maintaining the transitions between world of home and work (Emslie and Hunt, 2009; Morehead, 2001). At the same time the demands of the workplace can work to undercut the limited efficacy of work-family policies. In the restructured NPSS, for example, care workers are expected to be committed and willing to take responsibility for the aims of the organisation in a situation of excessive demands over which they have no control (Rasmussen, 2004, p. 523). 
These intersecting theoretical framings on gender and care work, on the political economy and labour process of the NPSS, and on work and family inform our analysis of how and with what consequences care workers manage paid and unpaid care work, and specifically of how the NPSS context shapes this negotiation of work and family.

\section{The Study}

Our focus in this paper is on the ways in which workers in three different NPSS organizations juggle work and care in the workplace. Our analysis is part of a larger study of the changing work experience of front-line care workers working in the NPSS sector in four comparable, restructured, liberal welfare states. The larger study which involved 13 case studies of NPSS organizations in Australia (3), Canada (4), New Zealand (3) and Scotland (3) undertaken between 2010 and 2013, aimed to investigate similarities and differences in the impacts of funding regimes and new managerial modes on NPSS workers (Baines and Cunningham, 2013). In this paper we draw on interviews with care workers and managers in three large multi-service organizations in Australia, New Zealand and Scotland that were conducted in 2010-12. We focus in the main on the commonalties of workers' experiences across the three organizations rather than on national context.

All three organizations provide a wide range of services across a number of sites including in the areas of housing/homelessness, aged care and disability, addictions, financial counselling and support, and family services. While both the Scottish and Australian organizations, ScotCo and AusCo, receive the majority of their funding through tendering for government contracts, NZCo relies mainly on fund-raising and philanthropic support. ScotCo is the largest organization with almost 1000 employees of whom $75 \%$ are women. Forty per cent work part-time or on a temporary or sessional basis. AusCo has around 800 employees of whom $80 \%$ are women. While employees are on a mix of full-time, part-time and casual contracts, almost half of the direct care staff were employed on casual or fixed term contracts. NZCo is the smallest organization with around 80 employees of whom a third work on a part-time or relief basis. Around 70\% of NZCo's employees are women.

\section{Case Study Approach}


Ethics approval was obtained at each of the relevant universities to conduct the research. The three organizations (and others) were initially approached because of their respective reputations as leaders in the field of social services and because they were generally seen as effective organizations. Our case studies involved a team of researchers (between two and five) in a short, concentrated study involving interviews, observations and a review of publically available documents. Our goal was to gather a wide range of perspectives from different parts of each organisation and from frontline workers, line managers or team leaders as well as senior managers on a variety of issues. These included the type of work undertaken, any changes in the work undertaken by the organizations and the workers as well as in the way work is organised over the last five years; the nature and extent of any violence at work, how workers managed their paid and unpaid care work, and the hopes and plans workers had for the future.

Consistent with qualitative research generally our aim was to illuminate processes at work rather than measure precise levels of oppression or to generalise to larger populations (Weigt \& Solomon, 2008, p. 623). Between three and five naturalistic observations in each organization, involving a mixture of formal and informal discussions with organization workers and service users, providing a basis to observe the flow of work, workload and service user-worker interactions (Kosny and MacEachen, 2010, p. 362). The data used in this paper came overwhelmingly from interviews, as the case studies did not involve observing the family life of workers.

Preparation for the study included an initial analysis of organization documents and discussion with senior management at each case study site. The first group of interviewees were selected on the basis of the informant perspective they could bring to the study with subsequent interviewees approached for their potential contribution to our study. Interviews typically took between 45-90 minutes and were audio-recorded. The team of researchers debriefed at multiple points in the day and iterated emerging themes into subsequent interviews and observations. This practice, alongside our extensive preparation, meant that we could clarify issues while in situ. Consistent with the use of this method in other studies, this iterative approach meant that saturation was achieved usually within 
three to five days, with further data collection confirming and deepening initial themes (see Bowen, 2008; Szebehely, 2007).

The gender and roles of interviewees at the three organizations are set out in Table 1 . We interviewed 52 individuals in all, including nine senior managers, 18 team leaders and 22 support/project workers. At all three organizations team leaders or line supervisors are directly involved in the delivery of front-line care. The ratio of female to male interviewees corresponded generally to the gender composition of each organization's workforce.

\section{Place Table 1 about here}

All interviews were transcribed verbatim and the researchers made written field notes of participant observations. A constant comparison method of data analysis was used until concepts and categories were identified and patterns emerged for the different groups of workers relevant to our focus of inquiry (Bazaley, 2009). While managing paid and unpaid care work was not the only theme of the interviews, it surfaced strongly for most interviewees and as an important context within which workers and managers negotiated and explained their work.

\section{Juggling paid and unpaid care work}

The findings are presented in terms of key themes that emerged around work and care in the three case study sites, in the context of low pay and lean work organization. Almost half of the frontline staff and line manager interviewees reported primary caring responsibilities for children or other family members, while several younger workers indicated their hopes of having children in the future. Other interviewees indicated they had adult children with varying levels of responsibility. Some informants' care responsibilities only emerged in discussion. One example was at NZCo, where a young worker first declared she had no family responsibilities and then described how she and her brother cared for a sister living with them who had serious mental health issues. The senior manager interviewees were less likely to talk about their own circumstances and where the work/family nexus was raised, discussion centred in the main on how their staff managed work and family.

\section{Pay}


Adequate pay is rarely conceptualised as a family-friendly benefit in the work and family literature nor is low pay typically seen as a family-hostile dimension of paid work. Yet the relative quantum of pay directly influences the capacity to provide unpaid care. The issue of low pay is a persistent one in social services workplaces. While there is some debate about whether there has been an unfavourable shift in pay (and employment conditions) in contracted out social services, what is clear is that in all three countries pay in the social services sector is very low in comparison with other workers (Cunningham and James, 2011, p. 229). In our three case study sites, the relatively low pay of social service work generally was an issue raised not only by staff but also by managers. Most compared social services wages to government workers doing similar work and noted the disparity in pay. Others compared sector wages to those in other low wage work. Simon, an AusCo senior manager, remarked 'we pay people that stack shelves in Safeway more than we pay our staff'.

At both AusCo and ScotCo pay rates were seen as typical in the national context of the social services sector, particularly for larger organizations. In an enterprise agreement at AusCo workers' salary levels were pinned at a very small premium above minimum industry rates. At ScotCo the regular cost of living increases had not been paid because of austerity measures put in place by (funding bodies) subsequent to the Global Financial Crisis. This was consistent with what was occurring across the Scottish sector (Cunningham, Hearne and James, 2013).

There was some divergence in views between local sector informants and managers as to where their particular organization stood in terms of comparison with similar sector organizations. These differences were particularly sharp in the case of NZCo. While the prevailing view of local sector informants was that NZCo wages were below the sector norm, NZCo senior managers and line managers insisted that their wages were at the 'mid-market 'range. ${ }^{2}$ Yet unlike ScotCo and AusCo where pay levels were very much constrained by government funding, NZCo relied in the main on private fundraising. Thus wages were set by the organization. Not only were professional staff, such as social workers, paid well below national norms, but the relative wages paid to different individuals were set by senior and line managers. Without a funding contract specifying wage levels across the organization, some frontline staff were frustrated by a lack of transparency. Belinda, a NZCo social worker, 
said she had no idea of her supervisor's or her colleagues' wages but that 'I think if I found out I'd probably get angry so I like to be naive!'

Normally, different wage rates paid to workers doing similar jobs reflects program funding paid under different government contracts (Baines, Charlesworth and Cunningham, 2014b, p. 22) rather than the managerial prerogative exercised at NZCo. While at ScotCo and AusCo differential pay rates were seen as an inevitable result of strict funding guidelines that prevented any cross-subsiding across programs, they were also seen as ad hoc and unfair by workers and managers. At AusCo, for example, Alison, a senior manager told us that there was quite a bit of staff resentment because case managers are employed at higher grades in better-funded disability programs than case managers in more poorly funded programs despite the work being essentially the same.

There was broad acceptance by many of the workers and by their managers that relatively low pay was the price for working in the sector. A dominant discourse, not only within organizations but in the sector and government funding bodies more generally, is that low pay is a trade-off for what is seen to be the intrinsic value of care work:

'But it's a case of people are willing to come and work for us because they've seen what we're doing and I think the ethos of what we're doing is more encouraging than just sort of a pay at the end of the week.' (Paul, ScotCo line manager).

John, an AusCo line manager, pointed out, however, that this trade-off might come at the cost of staff turnover: 'Periodically I lose staff because of the pay that we pay, and good staff'. Nevertheless in areas of increasing unemployment, such as in Scotland, having a job at all, even if low paid, was valued by a number of workers. As Leonie, a ScotCo project worker said: Well, I mean, I just kind of think I could get myself quite angry about it but I think I'm just lucky to have a job.'

Beyond any immediate recruitment and retention issues created by low pay in the sector, inadequate wages impact on the potential care responsibilities workers may assume. Liz, an AusCo youth worker told us that as much as she loved her job it would not be an option if she had a family in the future saying 'If I had a family, there is no way that I could afford to work here'. She described making do in her current situation by living in shared 
accommodation and buying clothes from second-hand shops. Indeed it is the absence of family responsibilities that makes it possible for some workers to remain in the sector:

'Fortunately I have got no kids or anything at the moment... I don't have any debts or anything so it's not an issue really' (Ian, AusCo team leader)

There was also explicit recognition by some managers about the impact low wages had on young people remaining in the sector after they took on family responsibilities and at the same time their willingness to make the 'gift' of working for low wages: As Simon, an AusCo senior manager, put it:

'They come out of the Uni and have a high social consciousness, but after five years you've got a boyfriend, you want to get married and buy a house, they can't afford to keep working at $\$ 30,000$ a year when you can get $\$ 60,000$ somewhere else. So there's a bit of a gift factor.'

An interesting theme to emerge was the extent to which paid care work (and the services provided) are directly subsidised by partners and families. We heard many such stories that ranged from people such as Peter a ScotCo support worker - 'I mean, I'm 36 years old and I'm still staying with my mother so it's about time I started to get more money' - to the more common experience of mainly female care workers being able to 'afford' to work in social services because of their partners' wages. As Janet, a NZCo social worker, notes:

'Fortunately my husband earns a reasonable sum and so what I earn is almost the cream, really'. This stereotype of women in care work as male-supported shapes the way both managers and workers can rationalise low pay (Palmer and Eveline, 2013, p. 262).

Less typically, James a NZCo support worker was able to work at a job he enjoyed because his wife, a primary school teacher, earned more than he did: 'If I was the sole breadwinner I couldn't probably afford to work here'. In an extreme case, Belinda, a NZCo social worker, related how low wages and the unreimbursed costs incurred doing her paid work were directly subsidised by her daughter. Belinda worked every second week at second site more than 100 kilometres away from the main site. Because NZCo does not cover her additional fuel costs, Belinda is dependent on her adult daughter for groceries and helping her get by: 
'My daughter lives up the road from me, I go there for food because I don't buy it because I can't, because I have to save my money for gas.'

\section{'Family-friendly' workplaces?}

The absence or presence of family-friendly working conditions is a central concern of the work and family literature (Bianchi and Milkie 2010; Pocock 2003). Such conditions can be understood as employee-orientated working conditions available to workers in their jobs for the purpose of helping them to balance paid work and family responsibilities (Campbell and Charlesworth, 2004, p. 40), including formal or informal working time and leave arrangements.

Within the social services sector, labour process scholarship has focused attention on the managerial models required by government contracts that produce lean work organisation (Baines, 2004, 2010; Cunningham, 2008; Richmond and Evans, 2005). The short-term nature and the high workloads such contracts bring in addition to the demands of different groups of vulnerable populations that the NPSS sector serve, operate together to produce familyhostile working arrangements (such as long hours, intermittent scheduling) and to undercut any family-friendly conditions that may be provided through industrial agreements, organizational policy or supportive line managers (Baines, 2011b).

Several interviewees spoke about being able to negotiate working time to meet care responsibilities. For example, Stewart, a ScotCo support worker, described how he had his roster arranged around his access visits to his daughter. For other workers, however, the experience of formal flexibility was that it was inflexible. Mary, an AusCo support worker said that the nature of her job supporting disadvantaged families meant she didn't use the organization's time in lieu policy. This was because '...as a case manager I don't think you'd have the time because all you'd be doing is coming back to 20 more voicemail messages all saying, "Help, I'm in crisis".' High workloads and inflexibility can also undercut basic workplace entitlements such as sick leave as many workers do not to want to leave their colleagues in the lurch by accessing leave. This was acknowledged by Lucy, an AusCo youth homelessness line manager, who said, 'it is pretty rare that people have sick leave in our team. Even when they are sick ... I have to force people to go home'. 
Where there is a lack of on-going flexibility available to help balance work and care, female workers may vote with their feet. Patricia, a ScotCo line manager, has a daughter with Asperger's whose care she manages through a patchwork arrangement of doing 12 hour shifts and having her mother and her former partner care for her daughter while she is at work. She is currently [just] managing around the fixed shifts but says: 'If I did leave at any point it would probably be because of my childcare reasons and I might be going part-time somewhere or somewhere with different hours.'

Patricia's situation also highlights the reliance on other family members to buffer the lack of flexibility at work. Further, while gendered expectations of self-sacrifice may characterise work in the NPSS (Baines et al, 2014b) such expectations can also lead to workers sacrificing their desire to be involved in the lives of those for whom they care, as has been Judy's experience at ScotCo. Judy, a social worker, has a seven year old and a two year old. When she works overnight shifts her parents, who also pick up and care for her seven year old on school days, come and stay with the children. This leads to a lot of guilt on Judy's part, not only having to rely on her parents to absorb the lack of flexibility in her job but also in failing her own parenting standards:

'...at times I feel that my children get the dregs of me ... I do feel at times that they come a poor second. My husband - he is in even a more demanding job than myself. I rely heavily on my mother and my father...the definition of a 'good enough' parent is that you're home to see them go to bed at night. You're there at night-time - well, I can't even do that sometimes.'

The professional knowledge Judy has of what constitutes positive family functioning contributes to her perceived failure to meet such standards herself. While she has a husband, it is Judy, also employed full-time, who takes on the managing of the unpaid care work and her own sense of unmet needs, thus reflecting the broader care regime in which women are held responsible for making family and employment 'work' (Weigt and Solomon, 2008, p. 645)

Both the labour process and the work and family literature underscore the importance of line managers, including their role in being supportive or not of their employees' unpaid 
caring responsibilities. In particular within the NPSS, supervisors can moderate the harsher aspects of work within the very real constraints of what is possible (Baines and Cunningham, 2011; Palmer and Eveline, 2013; Rubery and Urwin, 2011). Our data picked up a range of views held by line managers regarding their role of providing support to workers with care responsibilities. Many of the line managers interviewed expressed some conditional support for providing some employee-orientated flexibility where possible for those they supervised. David, a NZCo line manager, was however frank about his view that work/life balance is a concession too far:

'Working for an organization that is charitably supported, you can't expect extra concessions from the employer" Like what? 'Like wages, work-life balance...'

Several line managers referred to various forms of informal quid pro quo flexibility that were possible within the constraints of work demands. When asked about family-friendly arrangements, Doug, a NZCo senior line manager said 'We're fairly flexible ... there will come a time somebody might need to go to the dentist and they're applying for leave so we say, "Don't worry about it."' Interestingly Doug refers to time for self-care rather than caring responsibilities. However, it is clear access to this sort of flexibility is contingent on the particular supervisor. To gain informal support workers have to tap into individual relationships with supervisors which they have to both develop and maintain (Weigt and Solomon 2008, p. 636). The necessity of having to engage in relationship building both makes practical and on-going access to flexibility highly dependent on having a supportive supervisor (and on an individual worker's capacity to negotiate.

In some instances we found supervisors who were not just supportive of workers' rights to formal flexibility and needs for informal flexibility but who also acted as shock absorbers for their staff. Lucy, an AusCo line manager, describes her approach thus:

'So I'll often do a lot of the additional work so that my team can go home when they need to. But I'm pretty clear with them about recognising their TIL [time in lieu]; it's much harder in middle management to actually to take your own time off. It's much easier to back fill staff on the ground than my position.' 
In both ScotCo and AusCo the juggle between paid and unpaid care work appeared to be individualised by both workers and line managers, notwithstanding the presence of formal work-family policies. In NZCo, there were few policies with any access to ad hoc flexibility largely dependent on line manager discretion. In all three organizations workers used a variety of individual strategies to manage work and care that drew more on their accommodation of the demands of work than adjustments of the workplace to the demands of care. Such individualised strategies are necessarily limited as any significant workplace changes to support work-family balance require collective action (Bailyn, 2011, p. 20).

\section{Taking it home: hard \& blurred boundaries}

One useful way to theorise the ways workers manage and negotiate market work and unpaid care work is Clark's concept of 'border-crossings' between these usually separate spheres (2000). Such borders vary in permeability - the extent to which elements from other domains may enter; in flexibility - the extent to which a border may expand or contract; as well in the extent that borders might blend or merge (Clark, 2000, pp. 756-757). The strength of the borders and the direction of the spillover from one domain to another depend on how these various factors combine. We saw this in the way our informants talked about taking work home both emotionally and physically (or not). For some the spillover from work to home was seen as inevitable and part of the job, while others worked hard to keep clear boundaries between work and life outside.

Most interviewees spoke about how their care responsibilities were accommodated around the rigid and/or boundless demands of their work. Several line managers saw workers who made trade-offs, by 'choosing' part-time or temporary work to get the hours they wanted, as making individual choices about their working time. Indeed Angie, a ScotCo line manager, considered the decisions made by some of her staff to work on a temporary or sessional basis if they were unable to work weekends or nightshifts as evidence of the organization being flexible and responsive to the demands of unpaid care as it allowed workers to "keep their hands in', something she conceded was of also of advantage to the organization. The view that workers needed to adjust around the demands of the workplace was also reflected by Jim, a ScotCo support worker in the same work unit as Angie. He said: 
'...the needs of the service comes first and because this particular service is $24 / 7$ [and] working night shift [works] for some people it's easier for us to give them hours suitable to their home situation.'

At the same time, it was argued by a number of workers that the personal circumstances of workers might also limit the ameliorating impact of any organizational flexibility. Barb, an AusCo project worker, pointed out:

'...they're flexible to a point. I mean, it's written within the EBA [Enterprise Bargaining Agreement], so that's great, but there are still people who I know who are really struggling either as a single mum or that whole business of dropping their child off for childcare or if their child gets sick, once you've used your leave ... unless you actually take time off without pay, which is a real issue for people, particularly if they are a single mum.'

While Barb refers to 'people' as well as 'single mums' her description of colleagues juggling work and family highlights the assumption that it is the role of women to manage the intersections and borders between paid and unpaid care work. Indeed Emslie and Hunt critique Clark's work-family border theory as being gender blind and argue that gender is both central to any discussion about intersections between paid work and family life and embedded in the ways in which workers negotiate home and work life (2009, p. 153).

This raises the issue of how the men in our study saw the connections between work and home life. As in the Emslie and Hunt study (2009, p. 167) we found that despite the generally similar work and family circumstances of men and women, male workers tended to confine issues of caring responsibilities to raising young children, although not necessarily as the primary carer as reflected in this excerpt of an interview with Peter, a ScotCo project worker:

I: Do you have any care responsibilities at home?

Peter: Care?

I: $\quad$ Yeah, like taking care of kids or elderly parents?

Peter: I live with my partner and two children. I suppose two children I look after when my partner's working and things. 
Peter saw his role as picking up any slack in the absence of his partner rather than as a primary carer. While they differed in the extent to which they took on unpaid caring responsibilities, many of the men in our study tended to emphasise the importance of keeping a strong barrier between work and life outside. Indeed Doug, a NZCo senior line manager, told us that the kind of workers he looked for were those 'who [don't] get too worried about pretty much any damn thing other than doing absolutely the right thing by your client.'

Female workers were more likely to talk about the challenges in crossing the borders between work and care and, as illustrated by Judy above, tended to discuss current and varied concerns about juggling kids, other care responsibilities and paid work. Freda, a ScotCo support worker, also reflected on the permeability of the borders between work and care and the difficulty of maintaining separation between them given the nature of her paid work:

'I know it's meant to be ... you kind of draw a line but you don't, you get attached to people and you care for them. You wouldn't be doing this job if you didn't have that, if you didn't have that caring side in you.'

As well as the powerful gender norms embedded in working time and care regimes, the gender differences we picked up also reflect gender differences in work organisation not only in the case studies but in the sector generally (see Baines et al., 2014a). Many female front-line workers were located in unbounded work, such as homelessness, youth work and family support where they had to stay till the immediate problem was sorted and the borders between work and home adjusted around the demands of vulnerable clients. Lauren, a ScotCo support worker, articulates the acceptance by many workers that the demands of clients come first:

'I've known some service users who have been here for many, many years... You do form some kind of attachment to them and they've bared their soul to you ... Maybe it's just at this stage of my life that I just think maybe my God to turn my back and then they would have to start over with somebody else. But if you died tomorrow these people will have to do that anyway.' 
Several female care workers in unbounded support roles also identified with their clients, which blurred the lines between paid and unpaid care work and between work and personal identities. Sarah, a NZCo family crisis worker, said:

'I'm meeting people and they're telling me stuff and I'm thinking to myself, "I'm in the same boat". But I don't say that. Sometimes you share because it's nice to share so people know that you do know what they're talking about. But usually you don't say anything, you just think, "yeah, I know, darling, I'm in exactly the same position, even though I work."'

Several female interviewees talked about keeping their work and family domains separate. However this discourse seemed more characteristic of male line managers and workers, which may reflect the more technical tightly bounded work in which men are more likely to be located, such as drug and alcohol, day programs or residential programs. Fixed hours and shifts made for less permeable boundaries between work and home. However, this was also was seen by some interviewees as the result of positive learnt behaviour. In response to being asked if he found it easy to balance his home and work life, Peter a ScotCo project worker, stated 'I don't have any issues' but then went on to observe that was because he was one of the more experienced members of staff and that new staff may be stressed by the emotional demands of the work:

'...you'd need a heart of stone to not be touched by some of their issues, you know, and you can go home at night and think about people but I don't actually physically take anything home. I'm fine that way'.

Mario, a NZCo line manager in addictions, described his strategy for keeping work separate from his life outside: 'Well, when I'm not at work I forget about work'. Henry, a ScotCo group home worker, emphasised the lack of recognition by the organization for taking work home as a rationale for keeping work and home separate: 'First and foremost you don't get any extra thanks. I like my free time and I don't want to be doing work during that time. So, no, I don't do it.' But there are always exceptions and John, a ScotCo youth work team leader, gave his mobile number to his clients because they may need to reach him out of hours: 
'If you say to a client, "I'm always here for you," well, you have to follow that through, right? What I say to clients because half of them are young lads who just need to talk to someone because they're in that age group where they're fairly vulnerable, I say, "If you need to come in here every day to speak to me - do it." ...[and] I've got an old mobile that I had so I say to them, "That's my mobile number."'

Despite some strong gender differences in terms of crossing the border between paid and unpaid care work there was a widespread acceptance by both workers and line managers in all three organizations that paid care work trumps unpaid care work. For many of our interviewees, there was strong sense that prioritising the demands of service users 'goes with the territory' of working in the NPSS. Yet because women's lives are still generally more likely than men's to be dominated by the institution of the family, it is women who struggle most strongly between the demands of providing care in their own families and the demands of paid care work (Franzway 2003, p.7). Indeed, for several female interviewees, prioritising the demands of paid care work undercut some of the satisfaction and identity they gained from being 'good' family carers.

\section{Conclusion}

This paper contributes to the literature on workers in the NPSS sector through its focus on the impact of lean work organisation and low pay on the way paid front-line care workers negotiate their paid and unpaid care responsibilities. It also highlights the structuring effect of low pay on these negotiations and the role it plays as a family-hostile dimension of paid work. In this way the paper contributes to the growing interest in low-paid workers in the work and family literature through an analysis of how the provision of paid care services can depend on being subsidised by family members of care workers and may constrain younger workers desire to remain in the sector over the longer-term. This theme also relates more broadly to the argument that unpaid care in the household provides the social reproduction that underpins paid work (Folbre, 2001). As Acker argues, the non-responsibilities of organizations for social reproduction consigns caring to areas outside organizations' interests and thus maintains the ideal worker as unencumbered with organizational practices and policies continuing to reproduce this ideal (1998, p. 200). This phenomenon is 
sharply delineated in the NPSS, where the costs and overflow of the performance of paid care work are both subsidised by unpaid family work that supports workers, both materially and practically, and absorbed by the family so that for many workers paid care work crowds out the time and energy available for unpaid care.

The data from our three case studies suggests that the NPSS depend on paid care workers being essentially 'careless', that is unencumbered with family responsibilities, and not requiring breadwinning wages or supportive policies. Indeed, it could be argued that low pay and lean work organisation help to construct the ideal social service worker as unencumbered and provide little in the way of support to those who do not fit this ideal. This is paradoxical because care work is generally seen to be inherently family-friendly: because it is largely work that women do, often on a part-time basis. However, through the lean work policies and processes of the NPSS family responsibilities and care workers' desires to feel good about their unpaid care become invisible or at least unimportant in the workplace context.

Our analysis of the data show that for many care workers the unrelenting demands of service provision and low pay can make any long term commitment to working in social services unrealistic unless their paid care work can be subsidised and/or supported by their families. This has diverse effects for different groups of workers. Inadequate pay is the strongest factor underpinning younger workers seeing a limited future in the sector if they were to take on family responsibilities. Many female workers experience significant stress as they bend their unpaid care responsibilities to the demands of their paid work. Indeed selfsacrificing femininity at work can underpin self-sacrifice in the home including having to depend on other family members, sacrificing time with family leading to guilt at home (Baines, Charlesworth, Cunningham and Dassinger, 2012).

However many male workers, less likely to take on primary caring responsibilities, appear both less troubled by the prioritising of paid over unpaid care work and less likely to selfexploit for the job. Most of the male workers interviewed had erected clear emotional and physical borders between work and home confining paid care work to the workplace. This is not to argue that there are static and/or sharply delineated masculinities or femininities in the NPSS sector (Baines et al., 2014a), nor that the increased number of men working in the 
sector has not led to some men adopting more gender equal norms of caring. As noted above the location of most men in the three organizations in the more technical and tightly bounded work with fixed or regular hours made it easier to erect clear boundaries between work and home. In areas where the nature of the work more fluid and unbounded both men and women tended to display more of the 'feminine-associated, non-profit ethic and workplace norms' (Baines et al., 2014a, p. 16).

Nevertheless there is a widespread acceptance across different national and organization contexts that the work/family juggle is a personal responsibility rather than a structural problem caused by the demands of increasingly greedy organisations and social policy that fails to ensure governments adequately fund and support NPSS provision for workers. At the level of the workplace, supervisors can play an important role in buffering the impacts of paid care work especially through providing for some informal flexibility within the constraints of the demands of the workplace (Rubery and Urwin 2011). However the presence of formal policies does not necessarily guarantee practical access to family-friendly conditions. Moreover, the demands of paid care work and the way it is organised combine to create what are arguably family-hostile conditions.

Managing the borders between paid and unpaid care work at the three organizations is an individual (and largely invisible) issue with scant institutional responsibility taken to minimise the conflict between the demands of work and care. It is not just the absence of recognition and active support for working carers within social service organizations that makes it difficult for care workers to juggle their care responsibilities. The failure of social policy to promote the valuing and sharing of unpaid care work or to make adequate provision for workers in low-paid jobs such as care work (Lewis, 2001, p. 166) constrains the genuine choices that workers can make about balancing work and care (Lewis and Guilliari, 2005). Further, the lack of adequate public infrastructure including childcare and elder care also works to reinforce the individualised nature of unpaid caring responsibilities for all workers. The negotiation of work and unpaid care is not dissimilar to the invisible work required to make paid care work hold human services together (Charlesworth and Baines, 2011). Indeed the invisible work in paid care work flows on to the apparent invisibility of the unpaid care that care workers provide in their lives outside work. The failure by many NPSS organizations 
to acknowledge and accommodate their workers' unpaid care responsibilities has consequences not only for individual workers but also for meeting increasing demands for formal care.

\section{Notes}

${ }^{1}$ There are many terms used in the literature to evoke the juggling of market and family work, including workfamily integration, work-family reconciliation and work-family interference. While not without its flaws (see Moen, 2011; Lewis and Campbell, 2010), we use the term 'work-family balance' in an expansive sense to refer to the gendered business of managing work and unpaid care (Pocock et al., 2012).

2 We were told by 2 different social workers at NZCo that their wages were around NZ\$30,000 pa. Data from the Aotearoa New Zealand Association of Social Workers indicates the median wage for base grade NPSS social workers in the NPSS is around NZ\$44,000 pa (email communication 6 March 2015).

\section{Acknowledgements}

The authors are grateful to the case study organisations and the workers and managers who participated in the research. They also thank Dr Helen Marshall for her contribution to the case study data analysis.

\section{References}

Acker, J. (1998) The future of 'gender and organizations': connections and boundaries. Gender, Work \& Organization, 5, 4, 195-206.

Acker, J. (2006) Gender and organizations. In Handbook of the Sociology of Gender. Springer US, pp. 177-194.

Aronson, J., \& Smith, K. (2009) Managing restructured social services: Expanding the social? British journal of social work, 40, 2, 530-547.

Australian Bureau of Statistics (ABS) (2011) Australian Social Trends September 2011, Cat No. 4102.0

Bailyn, L. (2011) Redesigning work for gender equity and work-personal life integration. Community, Work \& Family, 14, 1, 97-112.

Baines, D. (2004) Caring for nothing: Work organization and unwaged labour in social services. Work, Employment and Society 18, 2, 267-295. 
Baines, D. (2010) If We Don't Get Back to Where We Were Before': Working in the Restructured Non-Profit Social Services. British Journal of Social Work, 40, 3, 928-945.

Baines, D. (2011a) Restructuring and Labour Processes under Marketisation. in Cunningham, I., \& James, P. (eds) Voluntary organizations and public service delivery : the employment outcomes of government outsourcing and their implications, Routledge.

Baines, D. (2011b) 'It was just too hard to come back': unintended policy impacts on workfamily balance in the Australian and Canadian non-profit social services. Community, Work \& Family, 14, 2, 233-248.

Baines, D., Charlesworth, S., \& Cunningham, I. (2014a). Changing care? Men and managerialism in the nonprofit sector. Journal of Social Work, DOI: $10.1177 / 1468017314548149$.

Baines, D., Charlesworth, S. \& Cunningham, I. (2014b) 'Fragmented Outcomes: International Comparisons of Gender, Managerialism and Union Strategies in the Nonprofit Sector' Journal of Industrial Relations 56, 1, 24-42.

Baines, D., Charlesworth, S., Cunningham, I. \& Dassinger, J. (2012) Self-monitoring, selfblaming, self-sacrificing workers: Gendered managerialism in the non-profit sector. Women's Studies International Forum, 35, 5,362-371.

Baines, D., \& Cunningham, I. (2011). 'White knuckle care work': violence, gender and new public management in the voluntary sector. Work, Employment \& Society, 25, 4, 760776.

Baines, D., \& Cunningham, I. (2013) Using comparative perspective rapid ethnography in international case studies: Strengths and challenges. Qualitative Social Work, 12, 1, 73 88.

Bazeley, P. (2009) Analysing qualitative data: more than 'identifying themes'. Malaysian Journal of Qualitative Research, 2, 2, 6-22.

Bianchi, S. and Milkie, M. (2010) Work and family research in the first decade of the 21st century. Journal of Marriage and Family, 72, 3, 705-725.

Bowen, G. A. (2008). Naturalistic inquiry and the saturation concept: a research note. Qualitative research, 8(1), 137-152. 
Charlesworth, S (2010) The regulation of paid care workers' wages and conditions in the non-profit sector: A Toronto case study. Relations Industrielles/Industrial Relations, 65, 3, 380-399.

Charlesworth, S. \& Baines, D. (2011) The Impact of Government Funding Models on Work Organisation and Employee Conditions in Non-Profit Community Services. Refereed proceedings of the 25th Conference of AIRAANZ, New Zealand Work \& Labour Market Institute, AUT University, 2-4 February 2011.

Charlesworth, S. \& Marshall, H. (2011) Sacrificing workers? The curious case of salary sacrificing in non-profit community services in Australia. International Journal of Public Sector Management, 24(7), 673-683.

Clark, S. C. (2000) Work/family border theory: A new theory of work/family balance. Human relations, 53, 6, 747-770.

Connell, R. W. (2005) A really good husband: Work/life balance, gender equity and social change. Australian Journal of Social Issues, 40, 3, 369.

Cunningham I (2008) Employment Relations in the Voluntary Sector. London: Routledge.

Cunningham, I. \& James P. (2011) ‘Public Service Delivery and the Voluntary Sector: Trends Explanations and Implications' in Cunningham, I., \& James, P. (eds) Voluntary organizations and public service delivery: the employment outcomes of government outsourcing and their implications, Routledge, p 225-237.

Cunningham, I., Hearne, G. \& James, P. (2013) 'Voluntary organisations and marketization: a dynamic of employment deregulation', Industrial Relations Journal, 44, 2, 177-188.

Daly, M. (2002) Care as a good for social policy. Journal of Social Policy, 31, 02, 251-270.

Duncan, G., and Chapman, J. (2010) New Millennium, New Public Management and the New Zealand Model. Australian Journal of Public Administration, 69, 3, 301-313.

Emslie, C., \& Hunt, K. (2009) 'Live to Work 'or 'Work to Live'? A Qualitative Study of Gender and Work-life Balance among Men and Women in Mid-life Gender, Work \& Organization, $16,1,151-172$.

England, P. (2005) Emerging Theories of Care Work Annual Review of Sociology, 31, 1, 381 399. 
England, P., Budig., M. and Folbre, N. (2002) Wages of virtue: The relative pay of care work. Social Problems, 49, 4, 455-473.

Evans, B., Richmond, T. and Shields, J. (2005) Structuring neoliberal governance: The nonprofit sector, emerging new modes of control and the marketisation of service delivery. Policy and Society 24, 1, 73-97.

Folbre, N. (2001) The Invisible Heart: Economics and Family Values. New York: New Press.

Folbre, N. (2006) Measuring Care: Gender, Empowerment, and the Care Economy Journal of Human Development, 7, 2, 183-199.

Folbre, N. (2008) Reforming Care Politics and Society 36, 3, 373-387.

Franzway, S. (2003) 'You Need to Care': The Work of Care between Home and Market, in Conference Proceedings, The Australian Sociological Association Annual Conference, University of New England, December 2003.

Kosny, A., \& MacEachen, E. (2010) Gendered, Invisible Work in Non-profit Social Service Organizations: Implications for Worker Health and Safety. Gender, Work \& Organization, $17,4,359-380$.

Lewis, J. (2001) The decline of the male breadwinner model: implications for work and care. Social Politics: International Studies in Gender, State \& Society, 8, 2, 152-169.

Lewis, J. and Campbell, M. (2008) What's in a name? 'Work and family 'or 'work and life 'balance policies in the UK since 1997 and the implications for the pursuit of gender equality. Social Policy \& Administration, 42,5, 524-541.

Lewis, J., and Giullari, S. (2005) The adult worker model family, gender equality and care: the search for new policy principles and the possibilities and problems of a capabilities approach. Economy and Society, 34, 1, 76-104.

McDonald, C. and Charlesworth, S. (2011) Outsourcing and the Australian Non-Profit Sector in I. Cunningham and P. James (eds) Voluntary organisations and public service delivery: the employment outcomes of government outsourcing and their implications, Routledge, pp 185-201.

Meagher, G. (2006) What can we expect from paid carers? Politics \& Society, 34, 1, 33-54. 
Moen, P. (2011) From 'work-family 'to the 'gendered life course 'and 'fit': five challenges to the field. Community, Work \& Family, 14, 1, 81-96.

Morehead, A. (2001) Synchronizing time for work and family: Preliminary insights from qualitative research with mothers. Journal of Sociology, 37, 4, 355-369.

Palmer, E. and Eveline, J. (2013) Sustaining low pay in aged care work. Gender, Work \& Organization, 19, 3, 254-275.

Pocock, B. (2003) The work/life collision: What work is doing to Australians and what to do about it. Federation Press.

Pocock, B. (2005) Work/care regimes: Institutions, culture and behaviour and the Australian case. Gender, Work \& Organization, 12, 1, 32-49.

Rasmussen, B. (2004) Between endless needs and limited resources: the gendered construction of a greedy organization. Gender, Work \& Organization, 11, 5, 506-525.

Richmond, T. and Evans, J. (2005) NGO-government relations and immigrant services: Contradictions and challenges. Journal of International Migration and Integration/Revue de l'integration et de la migration internationale, 6, 3-4, 513-526.

Rubery, J. and Urwin, P. (2011) 'Bringing the employer back in: why social care needs a standard employment relationship' Human Resource Management Journal 21, 2, 122137.

Scottish Social Services Council [SSSC] (2012) 2011 Scottish Social Services Workforce Data Report Available at: http://data.sssc.uk.com/data-publications/22-workforce-datareport/76-2012-scottish-social-services-workforce-data-report (Accessed 21 June 2014).

Statistics New Zealand (2012) Household Labour Force Survey: December 2012 quarter.

Szebehely M (2007) Carework in Scandinavia. Organisational trends and everyday realities. Conference paper, Fifth annual ESPAnet Conference, Vienna, September.

Warren, T., Fox, E. and Pascall, G. (2009) Innovative Social Policies: Implications for Work-life Balance among Low-waged Women in England. Gender, Work \& Organization, 16, 1, $126-$ 150. 
Weigt, J. and Solomon, C. (2008) Work-family Management among Low-wage Service

Workers and Assistant Professors in the USA: A Comparative Intersectional Analysis.

Gender, Work \& Organization, 15, 6, 621-649. 